DOI: $10.17805 /$ zpu.2015.3.12

\title{
Музыка на все времена: классическое наследие и современная культура*
}

\author{
Е. Н. ШАПИНСКАЯ \\ (ИНСТИТУТ КУЛЬТУРНОГО И ПРИРОДНОГО НАСЛЕДИЯ \\ Им. Д. С. ЛИХАЧЕВА)
}

В наше время существуют две важные социокультурные проблемы, которые затрудняют или вовсе не позволяют великим произведениям мировой культуры стать частью ценностного мира современного человека. Статья посвящена анализу данных проблем. Речь идет о небывалом распространении сферы массовой культуры, коммерческой по своей сути, процессов глобализации и медиатизации, а также об ослаблении чувства истории, характерном для культуры постмодернизма. Сегодняшняя культура по большей части живет по законам «культиндустрии» (Т. Адорно).

Для того чтобы понять проблемы существования культурного наследия, в том числе и музыкального, автор рассматривает социокультурный контекст наших дней, выделяет две области исследования музыкальной культуры, в особенности жанра оперы, который в наше время подвергается наибольшему количеству экспериментов. С одной стороны, необходимо осмысление классического наследия с точки зрения вечных проблем человеческого бытия, с другой - понимание специфики существования этих произведений как части живой ткани культуры нашего времени.

Доступность произведений классического искусства в лучших исполнениях, обеспеченная информационными технологиями, возможности филармоний и концертных залов иметь свои виртуальные пространства создают тот контекст, где доминируют эстетические представления, связанные с высшими достижениями культуры. Но этот контекст очень фрагментарен и капризен, что далеко не способствует формированию системы эстетических ценностей.

Таким образом, вновь становится очевидной необходимость воспитания подготовленного слушателя и зрителя. Никакие технологии, никакие масштабы оцифровки классики, никакие усилия энтузиастов не создадут благоприятного с эстетической точки зрения климата в социуме без интеграции усилий всех специалистов - ученых, теоретиков и практиков культуры, медиапрофессионалов, маркетологов, педагогов, - для того чтобы великое наследие нашей культуры заняло достойное место в жизненном мире современного человека.

Ключевые слова: высокая культура, искусство, классическое наследие, классическая музыка, массовая культура, опера, эстетическое воспитание.

\section{ВВЕАЕНИЕ}

Є икто не сомневается в значении классического искусства, культурного наследия ности молодежи. О важности культурного наследия для формирования здорового общества, бережно относящегося к традиции, опирающегося на опыт предшествующих поколений и культурную память, говорят ученые, педагоги и деятели культуры. Высшие ценности культуры и искусства, составляющие «золотой фонд» национальных культур, стали основой образовательных программ гуманитарного цикла в учеб-

* Работа выполнена при поддержке РГНФ (проект «Эстетическое воспитание в социокультурном контексте современной России - философия, теория, практика», грант № 14-03-00035a).

The article was prepared with financial support from the Russian Foundation for the Humanities (Project title "Aesthetic Education in the Sociocultural Context of Contemporary Russia: Philosophy, Theory, Practice”, grant No. 14-03-00035a). 
ных заведениях разного уровня и разной направленности. Эти прошедшие проверку временем произведения литературы и искусства становятся предметным полем ряда дисциплин, входящих в учебные планы, различные просветительские проекты, программы по духовно-нравственному воспитанию молодежи средствами искусства и т. А. Несомненно, образование опирается на высшие достижения культуры, в том числе и художественной, именно они становятся предметом различных образовательных стратегий в деятельности как учебных заведений, так и других учреждений культуры - театров, музеев, новых форм интерактивной проектной деятельности в этой области. На эти характерные для мировой университетской культуры черты не раз в своих исследованиях указывал Вл. А. Ауков (Ауков, 2005, 2009, 2012; Высшее образование ..., 2009), памяти которого были посвящены I Академические чтения в МосГУ «Мировая культура в русском тезаурусе» 27 марта 2015 г. (Иуков, 2015: Электронный ресурс).

Тем не менее в наши дни существуют две важные социокультурные проблемы, которые затрудняют или вовсе не позволяют великим произведениям мировой культуры стать частью ценностного мира современного человека. Эти проблемы связаны, во-первых, с небывалым распространением сферы массовой культуры, коммерческой по своей сути, с процессами глобализации и медиатизации и, во-вторых, с ослаблением чувства истории, характерным для культуры постмодернизма, получившей широкое распространение в последние декады XX - начале XXI в. Сегодняшняя культура по большей части живет по законам «культиндустрии» (термин Т. Адорно), Однако «новая», авангардная музыка, по мнению Адорно, «была антитезой распространению культурной индустрии за пределы отведенной для нее сферы» (Адорно, 2001: 45). «Пожалуй, переход к коммерческому производству музыки как товара массового потребления потребовал более длительного времени, нежели аналогичный процесс в литературе и изобразительном искусстве» (там же).

\section{МУЗЫКА И ФИАОСОФИЯ}

Аля того чтобы понять проблемы существования культурного наследия, в том числе и музыкального, изучению которого мы посвятили много лет, необходимо представлять себе социокультурный контекст наших дней, который во многом определяет как стратегии интерпретации классических музыкальных произведений, так и те практики введения классического наследия в поле массовой культуры, которые позволяют сделать эти произведения более доступными. Аоступностью обеспечивается коммерческий успех культурной индустрии, частью которой они неизбежно становятся в условиях массовизации культурного производства и сужения сферы элитарной культуры.

Можно выделить две области исследования музыкальной культуры, в особенности жанра оперы, который в наше время подвергается наибольшему количеству экспериментов, неизбежно находящихся во взаимодействии. С одной стороны, это осмысление классического наследия с точки зрения содержащихся в нем вечных проблем человеческого бытия, делающих великие произведения прошлого интересными и важными для любой эпохи и для любой социокультурной ситуации, с другой - понимание специфики существования этих произведений как части живой ткани культуры нашего времени, которое хочет видеть в них смыслы, релевантные для наших современников, передающиеся в тех формах, которые стали определяющими для культурных практик начала XXI в. 
На наш взгляд, для определения места классического музыкального наследия в наши дни необходимо обратиться не только к формальной стороне проблемы, которая является уделом музыковедов и театроведов, но и к философскому осмыслению тех общечеловеческих проблем и ценностей, которые наполняют различные музыкальные жанры. Музыка как проблемное поле человеческого бытия содержит в себе все общечеловеческие проблемы, которые передаются специфическим языком музыкальной формы. Рассмотрение музыки в предметной области философии культуры может показаться не самой подходящей областью культурного опыта для интеллектуальной рефлексии. Чувственная природа музыки более точно передается языком әстетики, а ее формальная сторона - языком музыковедения, если только вообще можно говорить о возможности передать сущность музыки вербальными средствами. Тем не менее в новом тысячелетии, когда пересматриваются многие философские понятия и идеи, когда возникают новые проблемные области и необходимость создания новой концептосферы, появляется и необходимость осмыслить эмоциональный и чувственный опыт, связанный с музыкой и приобретающий в наши дни новое измерение.

Мы живем в лиминальный период, когда возникает потребность создания новых пространств освоения мира, образовавшихся в результате пересмотра и стирания границ областей человеческого опыта, сконструировавших универсум человека Нового времени. «Конец философской эпохи, - пишет С. Аангер в своей замечательной работе «Философия в новом ключе», - наступает с исчерпанием ее движущих понятий. Когда все разрешимые вопросы, которые можно сформулировать в терминах данной эпохи, уже разработаны, мы остаемся только с теми проблемами, которые иногда называют "метафизическими”, обладающими неясным смыслом, с неразрешимыми проблемами, предельные формулировки которых таят в себе парадоксы» ( $А$ ангер, 2000: 14). Именно эти метафизические проблемы, соединенные с чувственной красотой и эмоциональным переживанием, содержащимися в музыкальной форме, стали предметом нашего исследования.

Существует общепринятое мнение о том, что эмоция является главным элементом в оценке музыки. Если принять как данность это утверждение, неизбежно встает вопрос о возможности вербальной передачи эмоций в целом и о тех языковых средствах, которые в большей степени способны на это. Сразу оговоримся, что, на наш взгляд, дискурсивная передача эмоционального мира возможна и, кроме того, необходима - иначе мы не предприняли бы этого исследования, а просто поделились бы с друзьями и знакомыми музыкальным материалом, который вызывает отклик в нашей душе и наводит нас на размышления о жизненно важных вещах. В то же время мы прекрасно осознаем, что задача наша очень сложна и требует поиска разных форм лингвистического выражения - писать об искусстве языком философской рефлексии сложно, но не невозможно, а чтобы такого рода текст доносил свою идею до разных кругов аудитории, необходимо использовать разные языки, в том числе и поэтический, создавая своего рода гипертекст, в центре которого стоят те музыкальные произведения, которые пережили свое время и прочно вошли в «золотой фонд» культуры.

\section{МУЗЫКА И ЯЗЗЫК}

Говоря о музыке, мы часто имеем в виду не условия ее создания, не исторический контекст или стилистику, не сложности формы, а чувства, которые она пробуждала и пробуждает в человеке. В ней чувства обретают форму, говоря словами С. Аангер, 
«чувства имеют определенные формы, которые постепенно становятся артикулированными» (там же: 91). В связи с этим встает вопрос о форме артикуляции чувств, о символике, через которую они становятся понятными, и в этом случае язык (мы не говорим сейчас о поэтическом языке, поскольку он действует по совершенно иным законам, нежели язык прозы - как художественной, так и научной) - далеко не лучший медиатор их глубины и интенсивности. «Все знают, что язык, - продолжает С. Аангер, - это самое жалкое средство для выражения нашей эмоциональной природы. Он довольно туманно и примитивно называет определенные постигаемые состояния, но совершенно не способен передать постоянно изменяющиеся формы, двусмысленности и глубины внутреннего опыта, взаимодействие чувств с мыслями и впечатлениями, воспоминания и эхо воспоминаний, мимолетную фантазию или ее простые рунические следы - все, что превращается в безымянный эмоциональный материал» (там же). Неадекватность современного языка для передачи всего богатства эстетического опыта подчеркивает и А. Рэнд: «Когда мы научимся переводить художественный смысл произведения искусства в объективные термины, то увидим, что искусство обладает ни с чем не сопоставимой силой в выявлении сущности человеческого характера. Художник в своих произведениях показывает обнаженной собственную душу, и, когда произведение находит отклик в вашей душе, вы, любезный читатель, делаете то же самое» (Рэнд, 2011: 43).

Но вербальный язык - это не единственный посредник передачи внутреннего мира человека, языки человеческой культуры многообразны и стремятся передать внутренний мир человека во всей его сложности различными выразительными средствами и системами символизации. Именно музыку и считает С. Аангер «самым высокоразвитым видом такой чисто коннотационной семантики» (Аангер, 2000: 92). Не вызывает сомнения способность музыки передавать эмоциональную сферу. «Поскольку формы человеческого чувства гораздо более сравнимы с музыкальными формами, чем с формами языка, музыка может раскрыть природу чувств детально и с такой правдивостью, которой язык не может достичь» (там же: 209-210). В моменты высочайшего эмоционального напряжения музыка оказывается гораздо более способной для экстериоризации внутреннего состояния человека. «Музыка и рыдание раскрывают уста и дают выход эмоциям сдерживающегося человека» (Адорно, 2001: 216). Т. Адорно анализирует такую ситуацию применительно к додекафонической музыке, где «слепой разум материала, как объективный элемент события, оставляет без внимания волю субъекта и при этом в конечном счете одерживает над ней победу в качестве неразумия» (там же: 200). Подобное доминирование иррационализма несомненно происходит в ряде случаев, когда «объективный разум системы не в силах справиться с чувственным феноменом музыки, ибо тот проявляется исключительно в конкретном опыте» (там же). Тем не менее человеческий интеллект стремится преодолеть и эту примордиальную силу - недаром музыка становилась предметом анализа таких мыслителей, как Ф. Ницше и С. Кьеркегор, А. Камю и С. Аангер.

Из этого мы можем сделать вывод о том, что чувственное и эмоциональное восприятие ни в коей мере не страдают от привнесения в них (или дополнения их) интеллектуального элемента. Напротив, в случае ощущения недостаточной полноты восприятия музыкального произведения обращение к его интеллектуальному постижению может только обогатить эмоциональную сферу, открыв в ней более тонкие оттенки. «Музыкальное понимание фактически не затрудняется из-за обладания активным интеллектом, ни даже той любовью к чистому разуму, которая известна как рациона- 
лизм или интеллектуализм; и vice versa здравый смысл и научная сообразительность не нуждаются в защите от какого-то бы ни было “эмоционализма”, который, как считают, является врожденным по отношению к музыке» (Мангер, 2000: 92). Более того, осмысление музыкального материала, воспринятого вначале на чувственно-эмоциональном уровне, представляет собой уникальную особенность музыки, «обратный психоэпистемологический процесс» (Рэнд, 2011: 50). «Во всех остальных искусствах произведения - физические объекты (то есть объекты, воспринимаемые нашими чувствами, будь то книги или живописные полотна), так что психоэпистемологический процесс идет от восприятия объекта к концептуальному пониманию его смысла, оценке в терминах главных личностных ценностей и соответствующим эмоциям. Общая схема такова: восприятие - концептуальное понимание - оценка - эмоция. В случае же музыки слушатель переходит от восприятия к эмоции, от эмоции - к оценке, от оценки к концептуальному пониманию» (там же).

\section{ЭКСКУРС В ОПЕРУ}

В наших исследованиях мы не обращаемся к «чистой» музыке, не найдя еще адекватных инструментов построения дискурсивного пространства вокруг этой сложнейшей формы культурной деятельности человека. Мы прибегаем к уже давно сложившейся в художественной практике форме сочетания слова и музыки, но не погружаемся в историю этого симбиоза, который уходит корнями в архаические культуры и связан с магическими культами и ритуалами. Такое исследование, несомненно, представляет большой интерес для истории культуры, но находится за рамками нашего интереса к музыкальной культуре наших дней, в которой музыкально-словесные жанры представлены рядом культурных форм, распространенных в разных пространствах современной культуры. «Речь и музыка, - пишет С. Аангер, - обладают существенно разными функциями, несмотря на их часто отмечаемое объединение в песне» (Мангер, 2000: 92).

Наш интерес среди всех этих форм сосредоточен на опере, в которой это объединение носит более сложный и в то же время более условный характер - в зависимости от качества либретто оперный нарратив может приобретать разные качества. Через во многом условный сюжет и зачастую чуждую современному слуху музыкальную стилистику слышен голос вечных проблем, которые беспокоят и волнуют человека вне зависимости от временной и пространственной обусловленности его бытия здесьи-сейчас. Эти проблемы и необходимо, на наш взгляд, выделить из богатейшего музыкального материала, который должен быть отобран для исследования. Именно опера, во всем богатстве ее архитектоники, доставляющая чувственное наслаждение, волнующая и в то же время призывающая к размышлению, стала главным предметом нашего исследования в книге, посвященной философскому осмыслению проблем, выраженных языком этого жанра (Шапинская, 2014a 1 ). С другой стороны, очень важным с эстетической точки зрения представляется проследить воздействие камерных жанров, в которых слово и музыка вступают в отношение неразрывной взаимодополнительности, - имеется в виду искусство романса, Lieder в немецкой традиции, которое проанализировано нами на примере вокального цикла Ф. Шуберта «Зимний путь» (Шапинская, 2014b).

Вторая группа проблем, касающихся классического музыкального (и поэтического) классического наследия, связана с судьбой классической музыкальной культуры в мире «посткультуры», для которой характерны плюрализм смыслов и деконструк- 
ция оппозиций. Интересно проследить модификацию столь условной музыкальной формы, как опера, в контексте наших дней, сформированном под влиянием расширяющейся сферы массовой культуры и постмодернизма с его культурным плюрализм-ом и деконструкцией традиционных бинаризмов. Выйдя за пределы оперных залов на фестивальные площадки и киноэкраны, став предметом туристического интереса и потребления, опера не могла не измениться и не приспособиться к законам «культиндустрии» и «посткультуры». Аля нас вопрос заключается не в благотворности этих изменений для оперы как жанра искусства, поскольку это - привилегия музыковедов и социологов культуры, а в том, как через достаточно традиционную форму оперного спектакля его создатели говорят с аудиторией о важнейших проблемах человеческого существования - о жизни и смерти, о любви и ненависти, о свободе и власти.

Наш экскурс в оперу проходит в нескольких плоскостях, «поверхностях», «plateau» (термин Ж. Аелеза и Ф. Гваттари) (пост)современной культуры. Одна такая поверхность - это попытка охарактеризовать контекст современной оперной практики, который мы определяем как «посткультура». Аругая поверхность пытается отойти от чистой синхронии и обратиться к истории, рассмотрев то, что постмодернистские теоретики называют утратой чувства истории, вернее, превращением истории в игру на исторический сюжет. Еще одна «plateau» - это собственно эстетическая составляющая музыкальных шедевров прошлого, их восприятие в контексте совершенно других эстетических ценностей и представлений, сформированных в эпоху массового производства и тиражирования культурных продуктов. В этой связи неизбежно возникает тема творчества в условиях постулируемой посткультурой исчерпанности культуры, а также тема саморефлексии художника, который в условиях избыточного культурного производства неизбежно задается вопросом о границах и возможностях интерпретации. Несколько «поверхностей» содержат разнообразную проблематику современной культуры, нашедшую воплощение в различных постановках как классических, так и современных оперных спектаклей: проблема текста и контекста, реальности и трансцендентности, соотношения гендерных ролей и феминизации культуры, судьбы «высокого» искусства в эпоху доминации массовой культуры.

Мы сознаем, что выбор примеров для анализа такого широкого круга проблем в их реификации в конкретной культурной форме не может избежать субъективизма (как и любой выбор материала для анализа в сфере искусства). В то же время размышления по поводу значимости классики в наши дни, вечности ее тем - любви и ненависти, верности и предательства, жизни и смерти - будут вызывать различные музыкальные и поэтические образы у читателей в зависимости от әстетических вкусов и «культурного капитала» (термин П. Бурдье). В информационную эпоху все музыкальные сокровища доступны (и это одно из ее позитивных качеств), и если у читателя возникнет желание погрузиться в этот прекрасный мир, он сформирует собственный тезаурус музыкальных примеров, возможно, совершенно отличных от наших, и по-другому осмыслит их - ведь речь идет о полисемантичных текстах, обладающих неистощимым кладом смыслов.

Технологии репродуцирования произведений классического музыкального наследия вводят в культурную практику не только известные произведения, но и утраченные шедевры, возвращенные культуре путем цифровых технологий. В качестве примера можно привести оперу А. Аренского «Рафаэль», которая обрела новую жизнь в рамках проекта «Возрождаем музыкальное наследие России». Эта опера, написан- 
ная в 1894 г., является подлинным выражением духа Серебряного века, с его интересом к эстетике прошлого, легенды, восточной экзотики.

Антон Аренский также обратился к теме, столь важной для художников во все времена, - теме красоты и любви, которая побеждает власть и насилие. Героем этой одноактной оперы стал великий гений Возрождения Рафаэль, имя которого предание связывает с Форнариной, простой девушкой, его натурщицей, естественная красота которой покорила художника. Вся опера, по сути дела, это выражение столкновения между свободой творчества художника и представителя Власти, который считает, что может распоряжаться творческой и личной судьбой художника. История, несомненно, романтичная и красивая, в ней слышатся отзвуки вечных вопросов отношения творца и общества, личности и массы, красоты живой и красоты, созданной искусством. Несомненно, «Рафаэль»- это видение художника Серебряного века далекой эпохи Возрождения, вовсе не претендующее на аутентичность, но выражающее свои эстетические идеи через идеализированную эпоху, представленную в духе символизма, столь любимого в век Аренского. Прекрасная музыка наполнена красотой реминисценций об итальянской песенной традиции и в то же время уводит нас в мир музыки XX в., использует все музыкальные средства для создания как нежной лирики, так и мощи финала, в котором участвуют оркестр и хор, сливающиеся в апофеоз красоты, победившей все препятствия и прославившей на века Художника - своего создателя.

Запись оперы и ее исполнение стали событием в музыкальной жизни нашей страны, знаковым для процесса возрождения наследия русских композиторов, который начался у нас благодаря усилиям тех, кто любит и ценит наследие нашей музыкальной культуры. После колоссального труда, связанного с восстановлением и оцифровкой текста оперы, записью на диск, «Рафаэль» был представлен публике в концертном исполнении. При всем достоинстве данного проекта возникает вопрос: значит ли доступность классического произведения его востребованность у публики? Несомненно, новые технологии, в частности оцифровка, создают новые возможности для классической музыки, способствуя расширению ее аудитории.

Тем не менее возможность слушать классическую музыку вовсе не означает увеличение понимания и любви к различным формам музыкального культурного наследия, часто требующим подготовленного зрителя/слушателя.

\section{МУЗЫКА И ИНФОРМАЦИОННЫЕ ТЕХНОАОГИИ}

У процесса тиражирования, который в наши дни заключается в основном в оцифровке произведений искусства, есть и противники, и сторонники. С одной стороны, доступность произведений классического искусства в лучших исполнениях, возможности филармоний и концертных залов иметь свои виртуальные пространства и знакомить с музыкой слушателей во всех уголках нашей (и не только) страны создают тот контекст, где доминируют эстетические представления, связанные с высшими достижениями культуры. С другой - этот контекст очень фрагментарен и капризен, что далеко не способствует формированию системы эстетических ценностей.

Эти черты интернет-пространства отмечают не только ученые, но и специалисты в области маркетинга исполнительских искусств. «Стремительный рост использования Интернета, - пишут известные специалисты в этой области Ф. Котлер и Аж. Шефф, - свидетельствует не только об изменениях в поведении потребителей, но и о изменении ценностей... Адриан Слыватски, запустивший в оборот выражение 
“миграция ценностей”, объясняет это таким образом: “Потребители делают выбор согласно своим приоритетам. Поскольку приоритеты меняются, и новые проекты представляют потребителям новые возможности, они делают новый выбор. Они перераспределяют ценности. Эти изменяющиеся приоритеты вместе со способами, с помощью которых они взаимодействуют с новыми предложениями конкурентов, являются тем, что вызывает, запускает или содействует процессу миграции ценностей”» (Котлер, Шефф , 2012: 449).

Как сторонники широкого использования технических средств в популяризации искусства, так и его противники соглашаются в том, что технология не может ни заменить, ни привить любви к искусству, в особенности если речь идет о классическом наследии. Никакие приемы маркетинга и пиара, никакие приемы визуализации и оцифровки новых и новых массивов культурных текстов сами по себе не приведут к тому, что человек предпочтет радио «Орфей» или телеканал «Культура» более развлекательным медиапространствам. «Какими энергичными ни были бы маркетинговые программы, люди вновь и вновь приходят на представление, делают искусство частью своей жизни благодаря пониманию его ценности, а также способности поддерживать, воспитывать и вдохновлять... если люди не любят и не понимают искусство по-настоящему, они вряд ли станут регулярно посещать театры и концерты и предпочтут довольствоваться другими способами проведения досуга» (там же: 636).

\section{ЗАКАЮЧЕНИЕ}

Таким образом, мы вновь возвращаемся к тому, о чем не раз писали раньше, к необходимости воспитания подготовленного слушателя и зрителя, который мог бы по достоинству оценить те - несомненно, громадные - возможности, которыми обладают современные средства технического воспроизведения. «Главным условием восприятия искусства и любви к нему является глубокое понимание его видов и форм, - пишут Котлер и Шефф, ссылаясь на проведенное в конце XX в. исследование влияния полученного человеком художественного образования на его посещение спектаклей и концертов. - Образование является ключом к тому, чтобы искусство стало значимой частью жизни человека» (там же: 636). Как бы вторя известному французскому социологу П. Бурдье, разработавшему концепцию культурного капитала, американские исследователи утверждают, что никакие технологии, никакие масштабы оцифровки классики, никакие усилия энтузиастов не создадут благоприятного с эстетической точки зрения климата в социуме без интеграции усилий всех специалистов - ученых, теоретиков и практиков культуры, медиапрофессионалов, маркетологов, педагогов, - для того чтобы великое наследие нашей культуры заняло достойное место в жизненном мире современного человека.

\section{ПРИМЕЧАНИЕ}

${ }^{1}$ В рецензии на эту книгу А. В. Костина обращает внимание на то, что концептуальные положения предпринятого исследования индивидуального информационного пространства напрямую связаны с тезаурусным подходом (Костина, 2015).

\section{СПИСОК АИТЕРАТУРЫ}

Адорно, Т. (2001) Философия новой музыки. М. : Аогос XXI век. 352 с.

Высшее образование и гуманитарное знание в XXI веке (2009) : монография-доклад Института фундаментальных и прикладных исследований Московского гуманитарного университета VI Международной конференции «Высшее образование для XXI века» (Москва, МосГУ, 19-21 но- 
ября 2009 г.) / В. А. Ауков, Б. Г. Юдин, Вл. А. Ауков и др. ; под общ. ред. В. А. Аукова и Вл. А. Аукова. М. : ИзА-во Моск. гуманит. ун-та. 560 с.

Костина, А. В. (2015) Культура в пространстве репрезентации // Знание. Понимание. Умение. № 1. С. 390-394. DOI: 10.17805/zpu.2015.1.38

Котлер, Ф., Шефф, Аж. (2012) Все билеты проданы: Стратегии маркетинга исполнительских искусств. М. : Классика-XXI. 688 с.

Аангер, С. (2000) Философия в новом ключе: Исследование символики разума, ритуала и искусства. М. : Республика. 287 с.

Ауков, В. А. (2015) I Академические чтения памяти Владимира Андреевича Аукова «Мировая культура в русском тезаурусе» [Электронный ресурс]// Научные труды Московского гуманитарного университета. № 2. C. 89-91. URL: http://journals.mosgu.ru/trudy/article/view/24 [архивировано в WebCite] (дата обращения: 13.04.2015). DOI: 10.17805/trudy.2015.2.5

Ауков, Вл. А. (2005) Мировая университетская культура // Знание. Понимание. Умение. № 3. C. $30-38$.

Ауков, Вл. А. (2009) Реформы образования и человеческий потенциал // Высшее образование для XXI века : VI Междунар. науч. конф. Москва, 19-21 ноября 2009 г. Аоклады и материалы. Ч. 1 / под общ. ред. И. М. Ильинского. М. : Изд-во Моск. гуманит. ун-та. 320 с. C. $238-245$.

Ауков, Вл. А. (2012) Тезаурусный анализ концепции высшего педагогического образования и предложения к ее обновлению // Тезаурусный анализ мировой культуры : сб. науч. трудов. Вып. 24 : Специальный выпуск : Высшее образование для XXI века: IX Междунар. науч. конф. Москва, 15-17 ноября 2012 г. : Аоклады и материалы. Симпозиум «Тезаурусный анализ мировой культуры» / под общ. ред. Вл. А. Аукова. М. : Изд-во Моск. гуманит. ун-та. 78 с. С. 48-69.

Рэнд, А. (2011) Романтический манифест: Философия литературы. М. : Альпина Паблишер. 199 c.

Шапинская, Е. Н. (2014а) Избранные работы по философии культуры. М. : Согласие ; Артем. $456 \mathrm{c.}$

Шапинская, Е. Н. (2014b) «Зимний путь» Шуберта в контексте современной культуры: вечные темы и безграничность интерпретации // PHILHARMONICA. International Music Journal. № 2. C. 272-283. DOI: 10.7256/1339-4002.2014.2.13536

Аата поступления: 15.04 .2015 2.

\section{MUSIC FOR ALL TIME: CLASSICAL HERITAGE AND CONTEMPORARY CULTURE}

\section{E. N. SHAPINSKAYA}

\section{(D. S. LikHachev Research InStitute for Cultural and Natural Heritage)}

There are two important sociocultural problems which at present obstruct or fully block the way for great works of world culture to form a part of the value treasury of a contemporary human being. Our article deals with these two issues, namely with an unprecedented spread of mass culture, a culture commercial by nature, accompanied by globalization and mediatization, and also with the weakening of the sense of history, which is characteristic of the culture of postmodernism. Contemporary culture mostly obeys the laws of the "Kulturindustrie" (T. Adorno).

To understand the issues cultural heritage (and musical heritage in particular) faces at the moment, we provide an overview of the current sociocultural context, outlining two areas of researching musical culture, especially the genre of opera, which undergoes the largest amount of experimentation. On the one hand, we need to view classical heritage from the standpoint of eternal issues of human existence, and in the other, it is vital to understand the particularities of these works as a part of the living contemporary culture.

The context dominated by aesthetic ideas and top achievements of culture is set up by easy access to the best performances of classical art, due to information technologies, philharmonies and concert 
halls and their virtual spaces. This context, however, is very fragmentary and changeable, which does not help the building of a system of aesthetic values.

It is thus evident that it is mandatory to educate a well-trained listener and spectator. No technologies or largescale digitization programs will on their own set up an aesthetically beneficial climate in the society. An integrated effort of various professionals - scholars, theoreticians and practitioners of culture, media specialists, marketing experts, educators - is required for the great heritage of our culture to assume an important place in the lifeworld of contemporary man.

Keywords: high culture, art, classical heritage, classical music, mass culture, opera, aesthetic education.

\section{REFERENCES}

Adorno, T. (2001) Filosofiia novoi muzyki [Philosophy of new music]. Moscow, Logos XXI vek Publ. 352 p. (In Russ.).

Vysshee obrazovanie i gumanitarnoe znanie $v$ XXI veke (2009) : monografiia-doklad Instituta fundamental' nykb i prikladnykb issledovanii Moskovskogo gumanitarnogo universiteta VI Mezhduna-rodnoi konferentsii «Vysshee obrazovanie dlia XXI veka» (Moskva, MosGU, 19-21 noiabria 2009 g.) [Higher education in the $21^{\text {st }}$ century: A monographical report of the Institute of Fundamental and Applied Studies, Moscow University for the Humanities, at the $6^{\text {th }}$ International conference "Higher Education for the 21 ${ }^{\text {st }}$ century" (Moscow, November 19-21, 2009] / V. A. Lukov, B. G. Yudin, Vl. A. Lukov et al.; ed. by V. A. Lukov and Vl. A. Lukov. Moscow, Moscow University for the Humanities Publ. 560 p. (In Russ.).

Kostina, A. V. (2015) Kul'tura v prostranstve reprezentatsii [Culture in the representational space]. Znanie. Ponimanie. Umenie, no. 1, pp. 390-394 DOI: 10.17805/zpu.2015.1.38 (In Russ.).

Kotler, Ph. and Scheff, J. (2012) Vse bilety prodany: Strategii marketinga ispolnitel' skikb iskusstv [Standing room only: Strategies for marketing the performing arts]. Moscow, Klassika-XXI Publ. 688 p. (In Russ.).

Langer, S. (2000) Filosofiia $v$ novom kliuche: Issledovanie simvoliki razuma, rituala $i$ iskusstva [Philosophy in a new key: A study in the symbolism of reason, rite, and art]. Moscow, Respublika Publ. 287 p. (In Russ.).

Lukov, V. A. (2015) I Akademicheskie chteniia pamiati Vladimira Andreevicha Lukova «Mirovaia kul'tura v russkom tezauruse» ["World Culture in the Russian thesaurus" - 1st Academic readings in the memory of Vladimir Andreyevich Lukov]. Naucbnye trudy Moskovskogo gumanitarnogo universiteta, no. 2, pp. 89-91. [online] Available at: http://journals.mosgu.ru/trudy/article/view/24 [archived in WebCite] (accessed 13.04.2015). DOI: 10.17805/trudy.2015.2.5 (In Russ.).

Lukov, Vl. A. (2005) Mirovaia universitetskaia kul'tura [World university culture]. Znanie. Ponimanie. Umenie, no. 3, pp. 30-38. (In Russ.).

Lukov, Vl. A. (2009) Reformy obrazovaniia i chelovecheskii potentsial [Educational reforms and the human potential]. In: Vysshee obrazovanie dlia XXI veka : VI mezhdunarodnaia nauchnaia konferentsiia. Moskva, 19-21 noiabria $2009 \mathrm{~g}$. : Doklady $i$ materialy [Higher education for the $21^{\text {st }}$ century: 6th International conference. Moscow, November 19-21, 2009 : Papers and materials]/ ed. by I. M. Ilinskiy. Moscow, Moscow University for the Humanities Publ. Vol. 1. 320 p. Pp. 238-245. (In Russ.).

Lukov, Vl. A. (2012) Tezaurusnyi analiz kontseptsii vysshego pedagogicheskogo obrazovaniia i predlozheniia $\mathrm{k}$ ee obnovleniiu [The thesaurus analysis of the conception of higher pedagogical education and suggestions for its updating]. In: Tezaurusnyi analiz mirovoi kul' tury [Thesaurus analysis of world culture] : A collection of articles. Issue 24 : Spetsial'nyi vypusk : Vysshee obrazovanie dlia XXI veka: IX Mezhdunarodnaia nauchnaia konferentsiia. Moskva, 15-17 noiabria 2012 g. : Doklady i materialy. Simpozium «Tezaurusnyi analiz mirovoi kul'tury» [Special issue : Higher education for the $21^{\text {st }}$ century: $9^{\text {th }}$ International conference. Moscow, November 15-17, 2012 : Papers and materials. Symposium "Thesaurus Analysis of World Culture"] / ed. by Vl. A. Lukov. Moscow, Moscow University for the Humanities Publ. 78 p. Pp. 48-69. (In Russ.). 
Rand, A. (2011) Romanticheskii manifest: Filosofiia literatury [The Romantic manifesto: A philosophy of literature]. Moscow, Al'pina Publisher. 199 p. (In Russ.).

Shapinskaya, E. N. (2014a) Izbrannye raboty po filosofii kul'tury [Selected works on the philosophy of culture]. Moscow, Soglasie Publ. ; Artem Publ. 456 p. (In Russ.).

Shapinskaya, E. N. (2014b) «Zimnii put'»Shuberta v kontekste sovremennoi kul'tury: vechnye temy i bezgranichnost' interpretatsii [Schubert's "Die Winterreise" in the context of contemporary culture: Eternal themes and the limitlessness of interpretation]. PHILHARMONICA. International Music Journal, no. 2, pp. 272-283. DOI: 10.7256/1339-4002.2014.2.13536 (In Russ.).

Submission date: 15.04.2015.

Шапинская Екатерина Николаевна - доктор философских наук, профессор, заместитель руководителя Экспертно-аналитического центра развития образовательных систем в сфере культуры Института культурного и природного наследия им. А. С. Аихачева, г. Москва. Адрес: 129366, Россия, г. Москва, ул. Космонавтов, д. 2. Тел.: +7 (495) 686-13-19. Эл. адрес: reenash@ mail.ru

Shapinskaya Ekaterina Nikolayevna, Doctor of Philosophy, Professor, Deputy Head, Expert and Analytical Center for the Development of Educational Systems in the Sphere of Culture, D. S. Likhachev Russian Research Institute for Cultural and Natural Heritage, Moscow. Postal address: 2 Kosmonavtov St., 129366 Moscow, Russian Federation. Tel.: +7 (495)686-13-19. E-mail: reenash@mail.ru 